\title{
Evaluation of banana germplasm against sigatoka leaf spot disease under natural conditions
}

\author{
S.R. PARDESHI*, N.B. SHAIKH AND J.S. CHAURE \\ Banana Research Station (M.P.K.V.), JALGAON (M.S.) INDIA
}

\section{ARITCLE INFO}

Received : 24.07 .2014

Accepted : 20.03.2015

\section{KEY WORDS :}

Epiphytotic, Genomic, Sigatoka leaf spot, Banana

*Corresponding author:

Email:

\begin{abstract}
Study on screening of germplasm of banana was under taken during 2008-09 and 2009-10 under natural ephiphytotic conditions. The observations were recorded on to sigatoka leaf spot index of banana. All cultivars under study from four genomic groups have recorded susceptible to highly susceptible reactions to the sigotika leaf spot disease (Mycosphaerella musicola) of banana. During both the years of study, all cultivars were recorded susceptible category, of disease reaction. Among the nine cultivars from AAA group, the respective range of PDI were 11.43 to 31.33 and 22.35 to 38.52 for 2008-09 to 2009-10. During both years of study, the highest PDI was recorded with cv. MAHALAXMI. The least PDI was recorded with cv. SHRIMANTHI. The cv. SAFED VELCHI (AB) recorded PDI above 20 and also recorded susceptible reaction. The four cultivars from $\mathrm{AAB}$ group recorded $\mathrm{PDI}$ in the range of 8.35 to 21.53 and 20.14 to 28.32 , respectively for 2008-09 and 2009-10.
\end{abstract}

How to view point the article : Pardeshi, S.R., Shaikh, N.B. and Chaure, J.S. (2015). Evaluation of banana germplasm against sigatoka leaf spot disease under natural conditions. Internat. J. Plant Protec., 8(1) : 204-207. 